\title{
Techno-Economic and Feasibility Assessment of Cryogenic Distillation Membrane (CDM) for Purification Natural Gas from $\mathrm{CO}_{2}$
}

\author{
Agra Y. Bachtiar ${ }^{1}$ *, Ayyub C. Annas ${ }^{1}$, Alifah N. A. Fajrin ${ }^{1}$, Muhammad H. Rizwan ${ }^{1}$, Indah R. \\ Kartikasari $^{1}$ \\ ${ }^{1}$ Institut Teknologi Sepuluh Nopember, Surabaya \\ Kampus ITS Sukolilo, Surabaya 60111, Indonesia
}

Received 3 July 2020; Accepted 13 August 2020

Available online 26 February 2021

\begin{abstract}
It is estimated that the energy demand in the world at 2050 will increase by $52 \%$ relative to 2017 . In Indonesia, it was predicted the deficit energy at natural gas sector occurred as much as 17.5 BSCF in 2020 and the deficit will increase to 3,327 BSCF in 2050. Nevertheless, the natural gas that Indonesia produced has impurities of $70 \% \mathrm{CO}_{2}$ and $0.6 \% \mathrm{H}_{2} \mathrm{~S}$, while the hydrocarbon only $28.1 \%$, that makes the heating value of natural gas become lower compared to common natural gas. Therefore, the process of separating the impurities of $\mathrm{CO}_{2}$ and $\mathrm{H}_{2} \mathrm{~S}$ from hydrocarbon is needed to increase the heating value and to get pure natural gas. One of alternatives that can solve the problem is Cryogenic Distillation Membrane (CDM). The CDM process integrates the process of cryogenic distillation and cryogenic membrane to separate impurities from hydrocarbon. It has been proven that cryogenic distillation can decrease $\mathrm{CO}_{2}$ concentration from $70 \%$ to $3 \%$, and rise up hydrocarbon purity from $70 \%$ to $95 \%$. Moreover, cryogenic membrane can increase the purity of natural gas from $95 \%$ to $98 \%$. Therefore, CDM process is expected as appropriate process to get rid the impurities and give high purity of natural gas. Based on the calculation through simulation using software ASPEN HYSYS, the CDM process is beneficial because it gives capture rate $\mathrm{CO}_{2}$ up to $99 \%$, decreases the purity $\mathrm{CO}_{2}$ from $70 \%$ to $0.001 \%$, reduces the purity $\mathrm{H}_{2} \mathrm{~S}$ from $0.6 \%$ to $0.02 \%$, increases natural gas purity from $28.1 \%$ to $98 \%$, raises the heating value from $284.5 \mathrm{Btu} / \mathrm{SCF}$ to $988.4 \mathrm{Btu} / \mathrm{SCF}$ and can generate valuable byproduct $\mathrm{CO}_{2}$ liquid.
\end{abstract}

Keywords: cryogenic, distillation, membrane, natural gas

\section{Introduction}

Nowadays, the world energy demand in 2050 is estimated to increase by $52 \%$ relative to 2017 . Indonesia as one of the rapidly developing countries in Southeast Asia appears to grow a similar pattern in the sector energy demand especially in natural gas sector energy demand. In the natural gas sector, Indonesia is predicted to have a deficit natural gas about 17.5 Billion Standard Cubic Feed (BSCF) in 2020 and it will increase by 3,327 BSCF in 2050 (BPPT, 2018). That is happened because natural gas has very crucial roles: as electric generation, vehicle fuel, fertilizer industry raw materials and as an environmentally friendly source of energy (Bakar \& Ali, 2010). To avoid the deficit energy, Indonesia as one of the largest natural gas producers in the world has amount of 144,063.7 BSCF natural gas that can fulfill the energy demand (BPPT, 2018). One source of natural gas is the Natuna Islands that has the largest capacity in Southeast Asia about 46,000 BSCF (Purwanto et al., 2016). Nevertheless, the impurity content of $70 \%$ of $\mathrm{CO}_{2}$ and $0.6 \%$ of $\mathrm{H}_{2} \mathrm{~S}$ while only $28.1 \%$ of hydrocarbon contained, makes the heating value of natural gas become lower compared to commercial natural gas (Purwanto et al., 2016). To solve that problem, many companies develop the processes of separating the impurities of $\mathrm{CO}_{2}$ and $\mathrm{H}_{2} \mathrm{~S}$ from hydrocarbon to get pure natural gas and to increase the heating value.

*Corresponding author

E-mail address: agrayubabachtiar@gmail.com 
Until now, many natural gas purification processes have been created to give high purity natural gas such as Pressure Swing Adsorption (PSA) and Absorption by Methyl diethanolamine (MDEA) (Bauer et al., 2013). Nevertheless, due to high impurities of $\mathrm{CO}_{2}$ up to $70 \%$ in natural gas, all these processes give higher production costs than the selling price. Therefore this problem made many natural gas processor companies decided not to continue develop all of these technology (Yeo et al., 2012).

Other alternative that can purify natural gas from $\mathrm{CO}_{2}$ is cryogenic technologies. By using these technologies, not only they generate high purity of natural gas, but also they generate valuable byproduct $\mathrm{CO}_{2}$ in liquid phase. The cryogenic distillation uses high pressure level therefore the $\mathrm{CO}_{2}$ liquid that produced would have a purity that reach up to 95\% (Yousef et al., 2019). These technologies also use a low-temperature refrigeration process, making it more applicable and feasible. As a result, many recent researchs explain the advantage and already develop cryogenic technologies to get higher purity of natural gas. However, purifying natural gas and produce $\mathrm{CO}_{2}$ liquid under cryogenic state can cause some issues. As an example, high pressure needs high compression power, refrigeration process needs large energy consumption for deep cooling (Song et al., 2019). In addition, at cryogenic state $\mathrm{CO}_{2}$ can turn into dry ice leading crucial issues in process like some pipelines blockage (Yeo et al., 2012). Hence, many studies focus to solve the problem that occurs in cryogenic technologies, since this problem is basically resulted from the high triple point temperature of carbon dioxide. Other study investigated a possible solution to evade frosting by increasing $\mathrm{CO}_{2}$ phase transition temperature.

One of the most common and effective separation processes that overcome $\mathrm{CO}_{2}$ in solid-phase issues is cryogenic distillation in which $\mathrm{CO}_{2}$ can be liquefied under low-temperature. The cryogenic distillation was successfully conducted without $\mathrm{CO}_{2}$ become solid phase, the maximum purity natural gas that reached was $94.5 \%$ (mol), which is quite lower than the standard purity (commonly higher than 97\%) needed for commercial use such as fuelling vehicles, fertilizer, or injecting into gas grid (Baccanelli et al., 2016). Hence, another cryogenic process needs to be developed depending on the condition operation of distillation columns to obtain much higher natural gas purity than the former configurations achieving higher than 97\% (mol). Therefore, this study develops the cryogenic distillation to get higher purity natural gas (Babar et al., 2019). On other hand, using cryogenic membrane with polyimides material can produce natural gas $98 \%$ of hydrocarbon and $99.8 \%$ of $\mathrm{CO}_{2}$ from natural gas consisting of $60 \%$ hydrocarbon and $40 \% \mathrm{CO}_{2}$ (Yeo et al., 2012). Due to that fact, by processing raw natural gas cryogenic membrane to get a higher purity of natural gas is very beneficial.

Hence, this study proposes an alternative process, Cryogenic Distillation Membrane (CDM) that integrates processes of cryogenic distillation and cryogenic membrane to separate impurities from hydrocarbon of natural gas. It has been proven that cryogenic distillation can decrease $\mathrm{CO}_{2}$ concentration from $70 \%$ to $3 \%$ and rise up hydrocarbon purity from $70 \%$ to $95 \%$; while by cryogenic membrane can increase the purity of natural gas. Not only that, using this process also can generate valuable by-product $\mathrm{CO}_{2}$ liquid (Yousef et al., 2019).

The aim of this study is to design the CDM process that is expected as appropriate process to get rid the impurities and give high purity of natural gas. The CDM process is predicted to give high capture rate $\mathrm{CO}_{2}$, decrease the purity $\mathrm{CO}_{2}$ in natural gas, reduce the purity $\mathrm{H}_{2} \mathrm{~S}$, increase natural gas purity, raise the heating value and can generate valuable by-product $\mathrm{CO}_{2}$ liquid. 


\section{Research Method}

\subsection{Process Description}

This section explains the process description of CDM to get pure natural gas. The CDM process designed use cryogenic distillation based on Yousef et al. (2019) integrates with cryogenic membrane based on Song et al. (2018). In addition, the CDM process designed by simulation using software ASPEN HYSYS to assure the possibility of application in reality (using Peng Robinson as fluid package).

Figure 1 illustrated the Block Flow Diagram (BFD) of CDM process. In the CDM process, there are 4 areas that will be through by natural gas to get high purity hydrocarbon in natural gas. These 4 areas are: 1) 4-Stage Compressor, 2) Cryogenic Distillation, 3) Cryogenic Membrane and 4) Liquefaction of $\mathrm{CO}_{2}$. To produce high purity natural gas, the feed of natural gas through 5 main processes. First, the 4stage compressor, its goal is to increase the temperature and pressure of the natural gas. Afterward, natural gas enters the refrigerant to produce natural gas with cryogenic state, which has pressure and temperature for about 49 bar and $-40{ }^{\circ} \mathrm{C}$. Then, natural gas goes through the cryogenic distillation to increase the purity of the natural gas and produce $\mathrm{CO}_{2}$ liquid as the by-product. Natural gas that coming out from cryogenic distillation, enters the cryogenic membrane to produce high purity natural gas (98.58\%) and $\mathrm{CO}_{2}$ gas. Both products go through liquefaction process to liquify the $\mathrm{CO}_{2}$ gas and this process produces $99.01 \% \mathrm{CO}_{2}$ liquid and high purity natural gas (98.58\%).

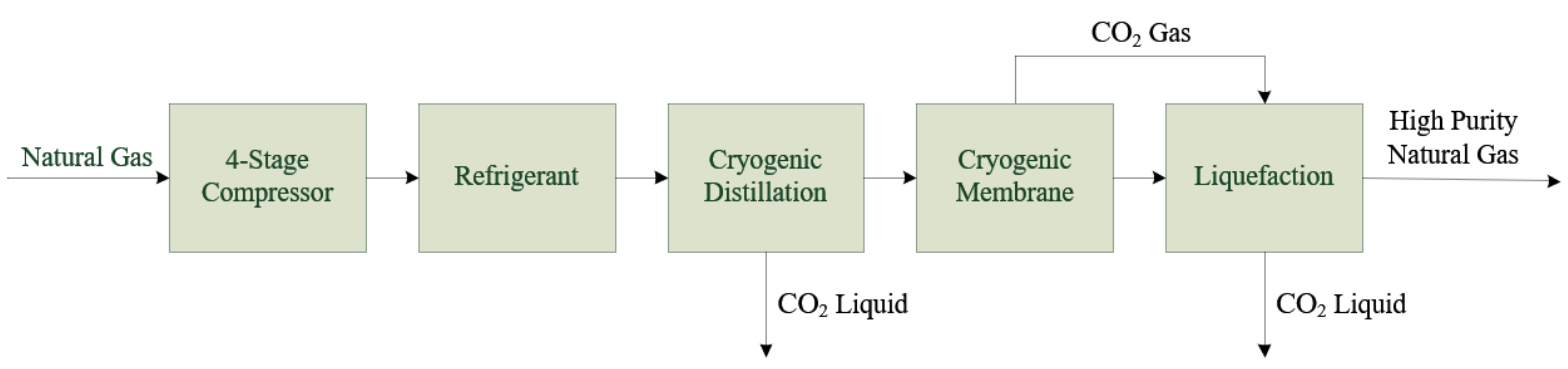

Figure 1. Block flow diagram of CDM.

Overall process of CDM for the simulation that used in software ASPEN HYSYS is illustrated in Figure 2. The feed (S1) of natural gas consists of $28.9 \%$ hydrocarbon, $0.6 \% \mathrm{H}_{2} \mathrm{~S}$ and $71 \% \mathrm{CO}_{2}$. The feed through the 4-stage compressor to increase the pressure and temperature from $100 \mathrm{kPa}$ and $25^{\circ} \mathrm{C}$ up to $4,908 \mathrm{kPa}$ and $160{ }^{\circ} \mathrm{C}$. The 4-stage compressor process displayed in Figure 3.

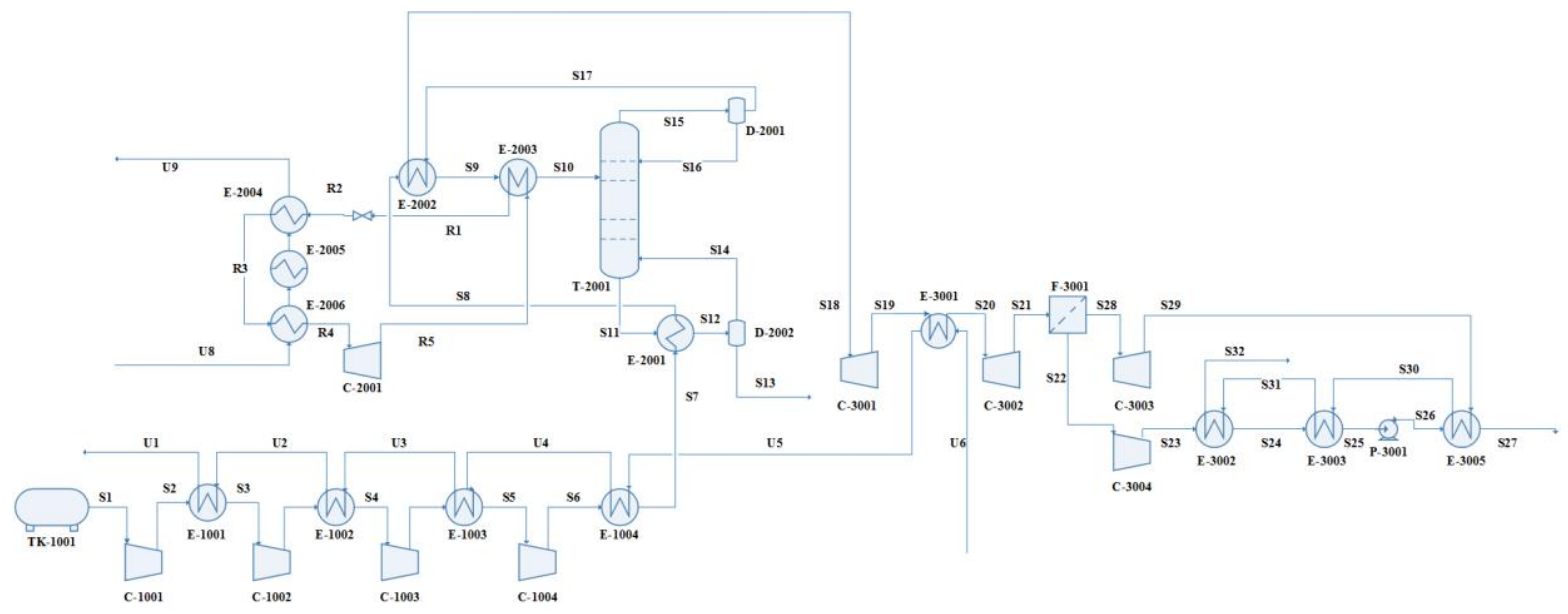

Figure 2. Process flow diagram of CDM. 


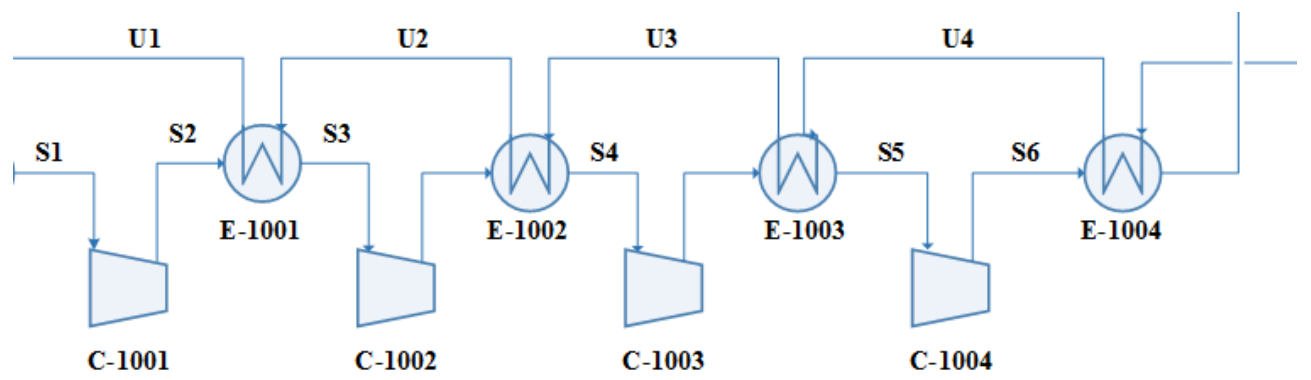

Figure 3. 4-Stage compressor process.

After the operating condition changes, the natural gas (S7) is sent to the cryogenic distillation area. The natural gas (S7) goes through to reboiler (E-2001) in the distillation column, pre-cooler heat exchanger (E-2002) and refrigeration heat exchanger (E-2003) that produce natural gas with the cryogenic state (pressure 49 bar and temperature $-40^{\circ} \mathrm{C}$ ) for entering the distillation column (T-2001), while in this process $\mathrm{CO}_{2}$ liquid is produced in stream S13. Figure 4 displays cryogenic distillation area that supported with refrigeration process.

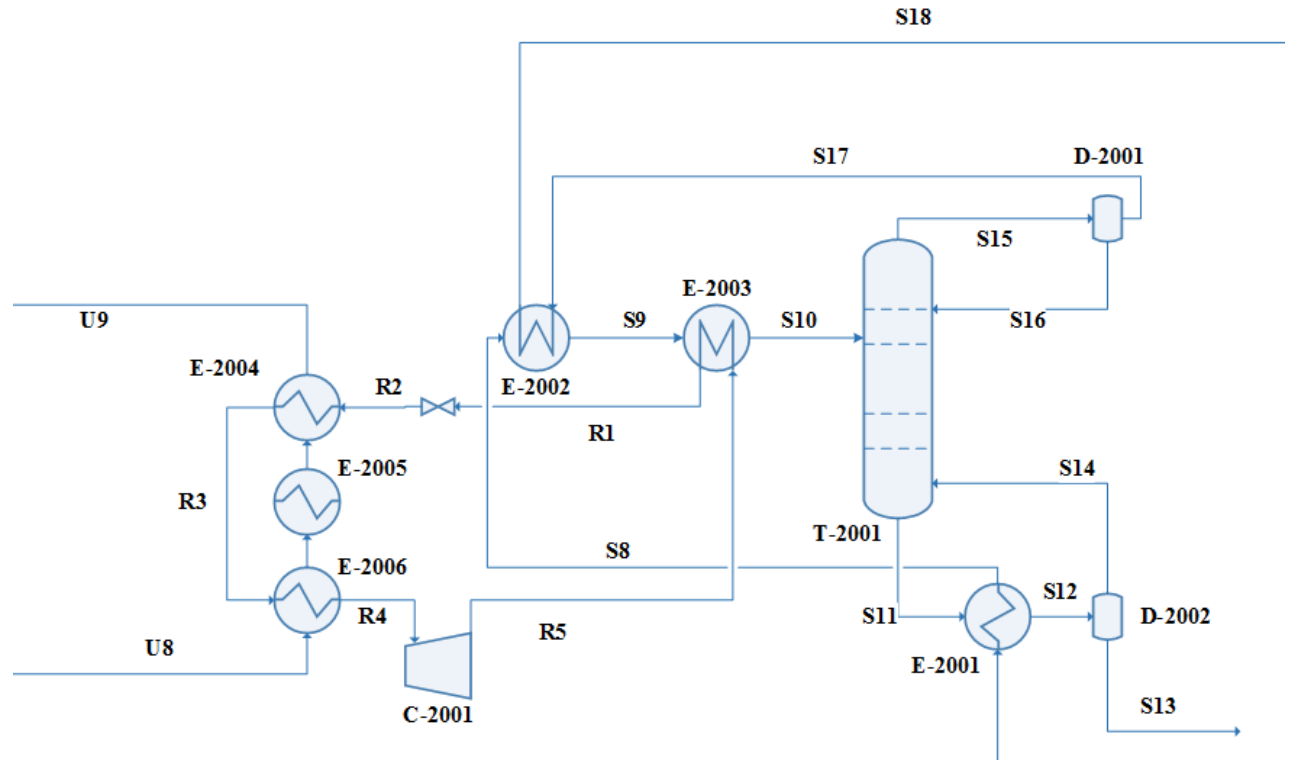

Figure 4. Cryogenic distillation \& refrigeration area.

The distillation column designed with 15 numbers of the tray with inlet natural gas at number tray of 7. All the data and operating conditions adopted for the column are listed in Table 1 - noting that all of these conditions are accurately optimized towards lowering the energy consumption and achieving the highest possible methane purity that can be accomplished with avoiding $\mathrm{CO}_{2}$ freezing.

Table 1. Distillation column's data selected in the proposed process.

\begin{tabular}{lr}
\hline \multicolumn{1}{c}{ Parameter } & Values \\
\hline Number of trays & 15 \\
Main stream inlet stage no. (from top) & 7 \\
Main stream inlet temperature $\left({ }^{\circ} \mathrm{C}\right)$ & -40 \\
Operating column pressure $(\mathrm{kPa})$ & 4,908 \\
Reflux ratio & 3.089 \\
Condenser temperature $\left({ }^{\circ} \mathrm{C}\right)$ & -76.95 \\
Reboiler temperature $\left({ }^{\circ} \mathrm{C}\right)$ & 12.09 \\
\hline
\end{tabular}


In the distillation column, the purity of the natural gas produced from the top stream (S17) increase up to $93.16 \%$ at $-78.52{ }^{\circ} \mathrm{C}$ and 45 bar while $\mathrm{CO}_{2}$ liquid is produced from the bottom stream (S13) and kept in storage with purity $99.08 \%$ at $12.7{ }^{\circ} \mathrm{C}$ and 48 bar.

Then the natural gas (S18) is streamed to a 2-stage expander to get the operation condition at 4 bar and $-60{ }^{\circ} \mathrm{C}$ for membrane process at F-3001. In addition, the electric energy can be utilized from the expander C-3001 and C-3002. The stream produced from the overhead stream (S29) contains sweet gas at 4 bar and $-30{ }^{\circ} \mathrm{C}$ with purity $98.58 \%$, while the stream produced on the bottom stream (S22) contains $\mathrm{CO}_{2}$ gas with purity $99.73 \%$ at $-30{ }^{\circ} \mathrm{C}$ and 1 bar.

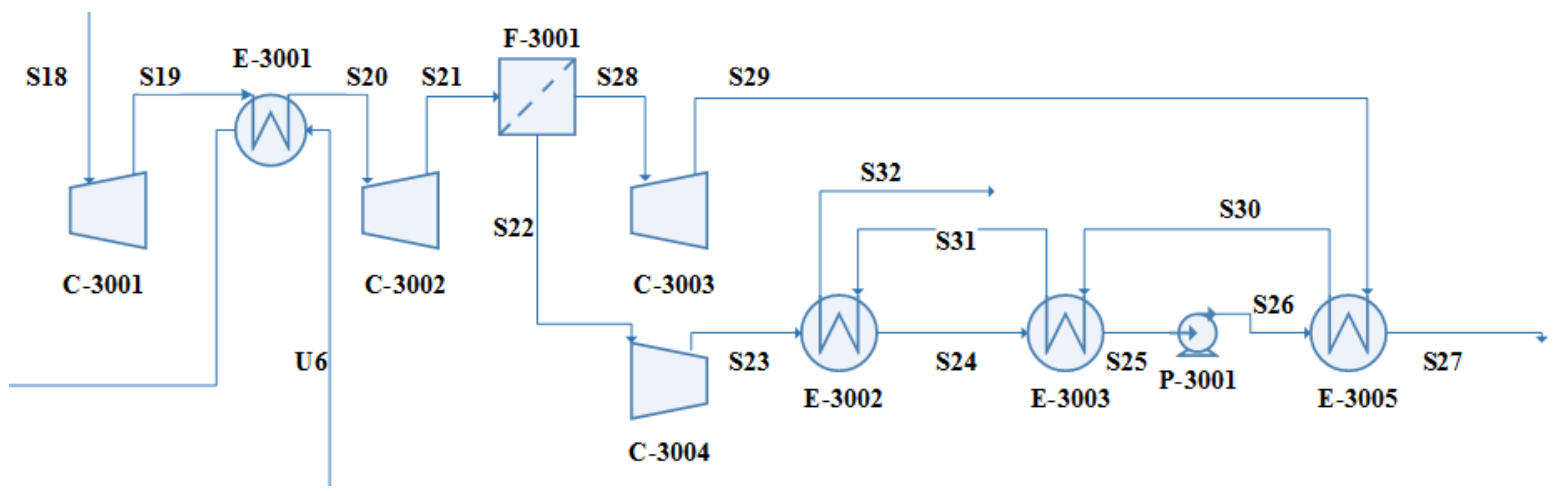

Figure 5. Membrane and liquefaction area.

The next step is liquefaction $\mathrm{CO}_{2}$ gas to become liquid as illustrated in Figure 5. Stream S29 is utilized as a counter-current cooling fluid in the liquefaction process. The liquefaction process produces purely natural gas (S33) with purity $98.58 \%$ hydrocarbon at $25{ }^{\circ} \mathrm{C}$ and 1 bar and $\mathrm{CO}_{2}$ liquid (S27) with purity $99.01 \%$ at $12.69^{\circ} \mathrm{C}$ and 48 bar.

\subsection{Feasibility Process Assessment Methodology}

In this study, we did a comparison natural gas that resulted from CDM with natural gas standard specification from Gas Processor Supplier Association (GPSA) (GPSA, 2004). To get accurate assessment, we also did a comparison CDM with other technologies for natural gas purification. The procedure we follow to calculate the main output of the simulation process, such as energy consumption at vary composition of hydrocarbon and $\mathrm{CO}_{2}$, calculated $\mathrm{CH}_{4}$ purity and loss. From HYSYS simulation, we obtained the $\mathrm{CH}_{4}$ purity after flashing. Regarding the methane loss of the present purification process, it was calculated using the following Equation (1):

$$
\mathrm{CH}_{4} \text { Loss }(\%)=\frac{\text { Mass } \mathrm{CH}_{4} \text { Feed }-{\mathrm{Mass} \mathrm{CH}_{4} \text { Cleaned }}_{\text {Mass } \mathrm{CH}_{4} \text { Feed }}}{\text { Meed }}
$$

Mass $\mathrm{CH}_{4}$ Feed is the mass flowrate of the methane existed in the feed biogas, measured in $\mathrm{kg} / \mathrm{s}$, while Mass $\mathrm{CH}_{4}$ Cleaned is the mass flowrate of the methane presented in the cleaned gas $(\mathrm{kg} / \mathrm{s})$. The first flowrate is inserted as an input, and the second one is resulted from the simulation tool.

In addition, $\mathrm{CO}_{2}$ Captured Ratio, which is an important parameter, was calculated using the following Equation (2):

$$
\mathrm{CO}_{2} \text { Captured Ratio (\%) }=\frac{\text { Mass } \mathrm{CO}_{2} \mathrm{Feed}-\mathrm{Mass}_{2} \mathrm{Cl}_{2} \text { Cleaned }}{\text { Mass } \mathrm{CO}_{2} \text { Feed }}
$$

To calculate energy demand, we have two sources of consuming energy, the refrigeration cycle and the compressors besides the pump. For the refrigeration energy, the refrigeration cascade cycle used in the process has a coefficient of performance (COP) of 0.866 (Yousef et al., 2019). Accordingly, the refrigeration cycle power consumption is calculated via the next equation: 
The total specific energy demand of the process is calculated as follow using Equation (3):

$$
\text { Specific Energy Demand }(k W)=\frac{\text { Power Refrigeration }+ \text { Power Pump }+ \text { Power Compression }}{\operatorname{COP}}
$$

The specific energy demand is calculated as $\mathrm{kWh} / \mathrm{Nm}^{3}$ cleaned natural gas. Also, the specific energy consumption can be calculated with respect to the raw natural gas flow instead of the cleaned one.

\subsection{Techno-economic Assessment Methodology}

In this work, the following tasks were performed: conceptual design of 300 Million Standard Cubic Feet per Day (MMSCFD) natural gas as feed with composition of $28.9 \%$ hydrocarbon, $0.6 \% \mathrm{H}_{2} \mathrm{~S}$ and $71 \% \mathrm{CO}_{2}$. While plant-level models used ASPEN HYSYS; the calculation of economy assessment was based on Turton et al. (2008). The fixed capital expenditure (CAPEX) and operational expenditure (OPEX) were estimated using the factorial method, where the total capital cost was related by factors that account for indirect costs (such as process machinery, pipe fitting, process instrument, erection, contingency, etc.). CAPEX was further related to the equipment cost by factors accounting for other field costs (for example: piping and instruments, installation, plant erection, civil work and building construction). The equipment purchase costs were in turn correlated to equipment sizes. Correlations used for estimating the purchase costs of most equipment as well as total capital costs were adapted from Turton et al. (2008). Equipment costs calculated based on historical correlations were adjusted to 2020 USD using Chemical Engineering Plant Cost Index (CEPCI) (Equation (4)):

$$
\text { Cost Equipment } 2020(C E 2020)=\frac{\text { Cost Equipment Base } \times \text { CEPCI } 2018}{\text { CEPCI } 2020}
$$

where cost equipment base for the equipment purchase cost, and the subscript stands for the specific year in which the value is estimated. CEPCI 2018 equals 603.1. The method, although originally derived from chemical process industries, is assumed to be applicable to estimate cost required for plants.

This study considered the Return of Investment (ROI), Internal Rate of Return (IRR) and Break Even Point (BEP) as the main economic performance indicators. To estimate the ROI, the Net Present Value (NPV) approach, which is defined in Equation (5) as the sum of the discounted annual cash flows (CF) throughout the system lifetime associated with investment, was calculated. Thus, it depends additionally on the current building/operation year, discount rate and total number of building and operation years. The remaining assumptions used in the economic performance assessment are presented in Table 2. This study also did a comparison in economy assessment with other common technologies. In addition, this study did a sensitivity analysis to ROI and IRR.

$$
N P V=\sum_{N=1}^{N=t} \mathrm{CF}_{\mathrm{N}} /(1+\mathrm{i})^{\mathrm{N}}
$$

where $\mathrm{i}$ is the discount rate and $\mathrm{N}$ is the project life in years. $\mathrm{CF}_{\mathrm{N}}$ is the cash flow in the $\mathrm{N}$-th year. 
Table 2. Financial assessment assumption for techno-economic assessment.

\begin{tabular}{lr}
\hline \multicolumn{1}{c}{ Parameter } & \multicolumn{1}{c}{ Values } \\
\hline Project start (year) & 2020 \\
Project length (yearion & 10 \\
Plant depreciation & Linear \\
Depreciation year & Until end period \\
Debt ratio & 0.4 \\
Equity ratio & 0.6 \\
Cost of debt & 0.08 \\
Cost of equity & 0.15 \\
Inflation rate (\%) & 10 \\
Discount rate (\%) & 10 \\
Construction time (year) & 3 \\
Investment cost distribution for & $20 / 30 / 50$ \\
first/second/third year of building period (\%) & \\
Plant salvage value & $10 \%$ of FC \\
Tax (\%) & 30 \\
Price natural gas (USD/MMBtu) & 1.72 \\
Price $\mathrm{CO}_{2}$ liquid (USD/kg) & 0.16 \\
\hline
\end{tabular}

\section{Results and Discussions}

\subsection{Feasibility Process Assessment}

Based on the simulation, the proposed cryogenic process converts raw natural gas into two valuable products: higher purity natural gas and liquid $\mathrm{CO}_{2}$. Natural gas (hydrocarbon-rich gas) is generated at relatively high pressure $(4,908 \mathrm{kPa})$ with high methane purity $(98.5 \%)$, suitable for a variety of applications: mainly for fueling vehicles and being injected into gas grid. Besides the main product, another output generated from the present configuration is liquid $\mathrm{CO}_{2}$ which has sufficiently high purity $(99.2 \%)$ and pressure $(4,908 \mathrm{kPa})$ to be feasible uses as a profitable by-produce. Higher purities than the resulted can be easily obtained by slightly raising number of trays in the column to match any $\mathrm{CO}_{2}$ purity. Also, the two products are already at high pressures which can save much more energy and costs when transported by using either compressors for natural gas or pumps for liquid $\mathrm{CO}_{2}$ in comparison with the traditional approaches that generally operate at low pressures.

Specifications of natural gas output from CMD process based on simulation are displayed in Table 3. In addition, Table 3 also shows comparison with standard specification of commercial natural gas based on GPSA. Based on Table 3, it was already proven that using CDM process can meet the requirement specification of natural gas based on GPSA standard.

Table 3. Comparison of natural gas specification as product with GPSA standard.

\begin{tabular}{|c|c|c|}
\hline Criteria & $\begin{array}{c}\text { GPSA } \\
\text { Standard }\end{array}$ & Cleaned Natural Gas \\
\hline Methane (\% mol) & Min. 75 & 98.5 \\
\hline Ethane (\% mol) & Max. 10 & 0.3 \\
\hline Propane $(\% \mathrm{~mol})$ & Max. 5 & 0 (Slightly exist) \\
\hline $\mathrm{H}_{2} \mathrm{~S}$ (grain/100 SCF) & Max. 20 & 13.36 \\
\hline $\mathrm{N}_{2}(\% \mathrm{~mol})$ & Max. 3 & 0 (Slightly exist) \\
\hline $\mathrm{CO}_{2}(\% \mathrm{~mol})$ & Max. 3 & 0.1 \\
\hline Heating value (Btu/SCF) & Min. 950 & 988.1 \\
\hline
\end{tabular}




\subsection{The Effect of Natural Gas Feed Composition}

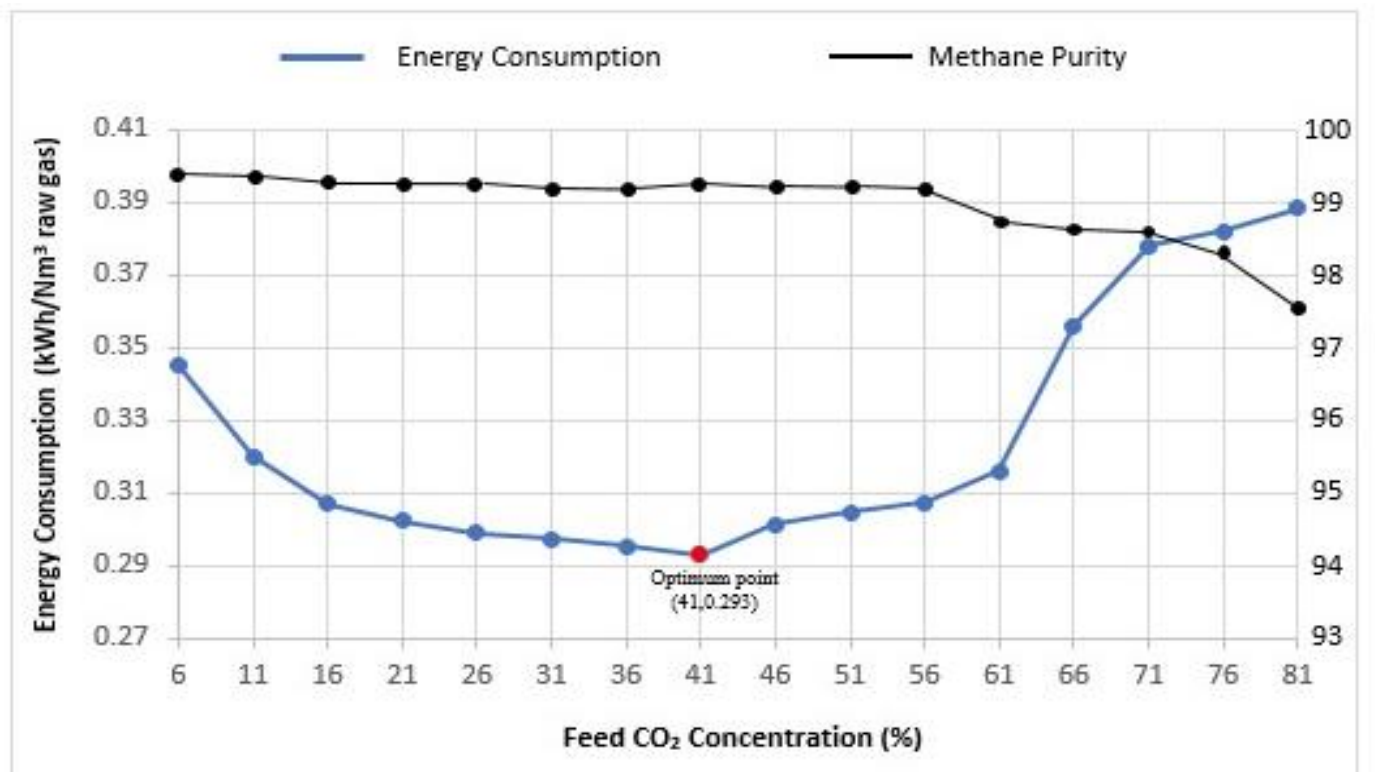

Figure 6. Effect of natural gas composition on methane purity and energy consumption based on simulation.

The quality of the feed natural gas refers to the number of hydrocarbons (methane) contained, so that a high percentage of methane means high quality natural gas. The quality of natural gas obtained is based on where the natural gas came from. Each place has different conditions that can affect the composition of natural gas produced. Thus, studying the influence of the variation in $\mathrm{CO}_{2}$ concentration in feed natural gas on the performance of the proposed process is very important to consider.

During examining the impact of changing inlet composition, the whole conditions of the process are constant, including column operating conditions, while the purity of the methane produced depends on the concentration of $\mathrm{CO}_{2}$ contained. The more $\mathrm{CO}_{2}$ contained, the smaller the purity of methane produced. As shown in Figure 6, based on the simulation, the energy consumption (measured in $\mathrm{kWh} / \mathrm{Nm}^{3}$ raw natural gas) is represented together with the methane purity at different $\mathrm{CO}_{2}$ concentration, ranging from $6 \%$ to $81 \%$ in the feed natural gas. The results show that when producing high purity of methane, the least energy consumption occurs at inlet $\mathrm{CO}_{2}$ concentration of $41 \%$ (mol) with $0.293\left(\mathrm{kWh} / \mathrm{Nm}^{3}\right.$ raw natural gas) and $99.28 \%(\mathrm{~mol})$ of methane purity produced compared to the entire range of changing composition. The reason for this is that, starting from the highest concentration of $\mathrm{CO}_{2}(81 \%)$, decreasing the concentration in the feed natural gas reduced the energy consumption until $41 \%$. Because this drop in concentration enhances the flowrate produced from the top of the column, thus further increase of the cooling effect induced in pre-cooler heat exchanger and then lowering the refrigeration penalty and energy consumption in cooler. Of course, the increase in the flow rate of this top product makes, on contrary, a slight growth in the refrigeration demand of column's condenser, but the reduction in the cooler is greater than the increase in the condenser, resulting in a drop in the total energy consumption by the process between the concentration of $81 \%$ and $41 \%$.

On the other hand, below $41 \% \mathrm{CO}_{2}$ concentration, the cooler, which is located just before the column, is no longer needed because the refrigeration potential in the top product stream will be sufficient to decrease the inlet column stream temperature to the required temperature $\left(-40^{\circ} \mathrm{C}\right)$ by exchanging heat in pre-cooler heat exchanger. Hence, lowering the concentration will further increase the product flow at the top of column as mentioned and, as a result, the energy consumptions in the condenser lead to a higher overall process consumption. Therefore, as shown in the Figure 6, between the two contrary trends (upwards and downwards), the turning point engenders which is considered as the optimum 
concentration to run the proposed process is at $41 \%$ (mol), at which the energy consumed will experience its lowest levels of energy requirements. It is worth mentioning that there is no impact on frosting in the column resulted from changing the carbon dioxide concentration in the feed natural gas; the column is kept safe from freezing during the whole study.

\subsection{Comparison of Process Assessment with Other Common Processes}

In this section, a comparison of CDM with other technologies such as MDEA and PSA for natural gas purification was discussed. From Table 4, CDM process give many advantages such as increase the natural gas purity to $98.5 \%$, high capture rate $\mathrm{CO}_{2} 99 \%$, reduce $\mathrm{H}_{2} \mathrm{~S}$, raise the heating value up to 988 $\mathrm{Btu} / \mathrm{SCF}$, give high purity $99 \% \mathrm{CO}_{2}$ liquid, low hydrocarbon losses only $0.5 \%$ and lower energy demand compared with other commercial processes.

Table 4. Process assessment comparison of CDM with other common processes.

\begin{tabular}{lrrr}
\hline \multicolumn{1}{c}{ Criteria } & \multicolumn{1}{c}{ CDM } & \multicolumn{1}{c}{ MDEA } & \multicolumn{1}{c}{ PSA } \\
\hline $\mathrm{CO}_{2}$ liquid purity $(\% \mathrm{~mol})$ & 99.01 & 93 & 75.89 \\
Natural gas purity $(\% \mathrm{~mol})$ & 98.5 & 98 & 95 \\
Hydrocarbon losses $(\% \mathrm{~mol})$ & 0.51 & 1 & 2 \\
$\begin{array}{l}\text { Energy demand } \\
\text { (kWh/Nm} \mathrm{Nm}^{3} \text { natural gas) }\end{array}$ & 0.38 & 0.43 & 0.5 \\
Reference & & & \\
& This & (Yousef et & (Bauer et \\
& Report & al., 2019) & al., 2013) \\
& Based & & \\
\hline
\end{tabular}

The MDEA and PSA process do not give many advantages although it was already proven these processes can give high purity natural gas. As long as the process uses a chemical substance to purify the natural gas, due to high impurities of $\mathrm{CO}_{2}$ up to $70 \%$ in natural gas, the MDEA and PSA process need a lot of energy and more chemical supplies to separate the $\mathrm{CO}_{2}$ (Bauer et al., 2013). CDM technology requires only as much energy as $0.39 \mathrm{kWh} / \mathrm{Nm}^{3}$ cleaned natural gas lower than other commercial technologies, such as Pressure Swing Adsorption $\left(0.65 \mathrm{kWh} / \mathrm{Nm}^{3}\right.$ cleaned natural gas) and MDEA Absorption (0.43 kWh/ $\mathrm{Nm}^{3}$ cleaned natural gas) (Yousef et al., 2019). PSA and MDEA are commonly known as processes for purification natural gas (Bauer et al., 2013). Nevertheless, when the high impurities of $\mathrm{CO}_{2}$ up to $70 \%$ in natural gas, all these processes give the production costs higher than the selling price. Hence, the CDM process has an advantage when process natural gas with high impurities of $\mathrm{CO}_{2}$. Due to utility for electricity generation, the smaller the energy needed, the lower the emissions released. This is relevant because a combustion process is needed to produce energy used during the natural gas processing. During the combustion process for electric generation, $\mathrm{CO}_{2}$ and other gases will come out into the environment as emissions. In addition, another valuable by-product $99 \% \mathrm{CO}_{2}$ liquid is also produced in the CDM process. It is important to consider its purity which can turn the $\mathrm{CO}_{2}$ to liquid for profitable one rather than being gas emission (Pittalà, 2018). On the other hand, the conventional methods usually require extra costly conditioning and processing on the emitted $\mathrm{CO}_{2}$ in case of generating it in liquid phase (Yeo et al., 2012). Many experts did not use cryogenic distillation because of the solidification of $\mathrm{CO}_{2}$ in the column, but using the right condition operation can prevent that issue. Compared with other technologies such as MDEA and Pressure Swing Adsorption (PSA) that produce $\mathrm{CO}_{2}$ that do not meet specifications (only about $75.89 \%$ and $93 \%$ ), so automatically, the $\mathrm{CO}_{2}$ from this process is disposed and cannot be sold (Yousef et al., 2019). Moreover, liquefying $\mathrm{CO}_{2}$ directly from distillation column in $\mathrm{CDM}$ process saves itself significant amount of capital and energy cost compared to other process such as liquefaction by refrigeration process.

Hence, CDM more beneficial because lower energy demand and does not need chemical supplies for treating natural gas with high impurities. Furthermore, based on simulation if the impurities in the 
feed become higher than $70 \%$, then the CDM process only need make the distillation column with more tray and does not give significant effect to operational process.

\subsection{Techno-economic Assessment}

This report did economic assessment for CDM process to know the feasibility CDM in economy aspects. To evaluate properly the performance of the suggested process against other common technologies approaches for purify natural gas, cost assessment is also conducted in this work. Since the proposed system is relatively a novel process in natural gas upgrading field, conducting economical evaluation in terms of calculating accurately its investment cost is needed. In this report, the economic analysis calculation method is techno-economic analysis. By using techno-economic analysis, CAPEX, OPEX, ROI, IRR, NPV and PBP can be predicted by using cost of equipment from $\mathrm{CDM}$ process as a basis calculation. As result for economic analysis showed in Table 5.

Table 5. Economic analysis of CDM.

\begin{tabular}{lr}
\hline \multicolumn{1}{c}{ Parameter } & \multicolumn{1}{c}{ Values } \\
\hline CAPEX (USD) & $344,472,322.45$ \\
OPEX (USD/Year) & $155,772,528.14$ \\
Return of Investment (\%) & 23.80 \\
Net Present Value at year-20 (USD) & $1,329,433,108.60$ \\
Payback Period (Year) & 4.21 \\
BEP (\%) & 0.16 \\
\hline
\end{tabular}

Table 6. Comparison of the economic analysis and other processes.

\begin{tabular}{lrrr}
\hline \multicolumn{1}{c}{ Criteria } & CDM & \multicolumn{1}{c}{ MDEA } & \multicolumn{1}{c}{ PSA } \\
\hline $\begin{array}{l}\text { CAPEX } \\
\text { (USD/Nm }{ }^{3} \text { cleaned natural gas) }\end{array}$ & $1,359.790$ & $1,618.96$ & $2,022.47$ \\
$\begin{array}{l}\text { Energy cost } \\
\text { (USD/Nm }{ }^{3} \text { cleaned natural gas) }\end{array}$ & 0.012 & 0.0137 & 0.0160 \\
ROI (\%) & 23.8 & 20.8 & 19 \\
PBP (years) & 4.21 & 4.8 & 5.1 \\
Reference & This Report & Yousef et al., & Bauer et al., \\
& Based & 2019 & 2013 \\
& Simulation & & \\
\hline
\end{tabular}

The result of the economic analysis for the CDM process compared to other processes displayed in Table 6. From the comparison of economic analysis, it can be concluded that using CDM process is more beneficial due to: cheaper CAPEX, lower OPEX, higher ROI and faster PBP compared with other commercial processes.

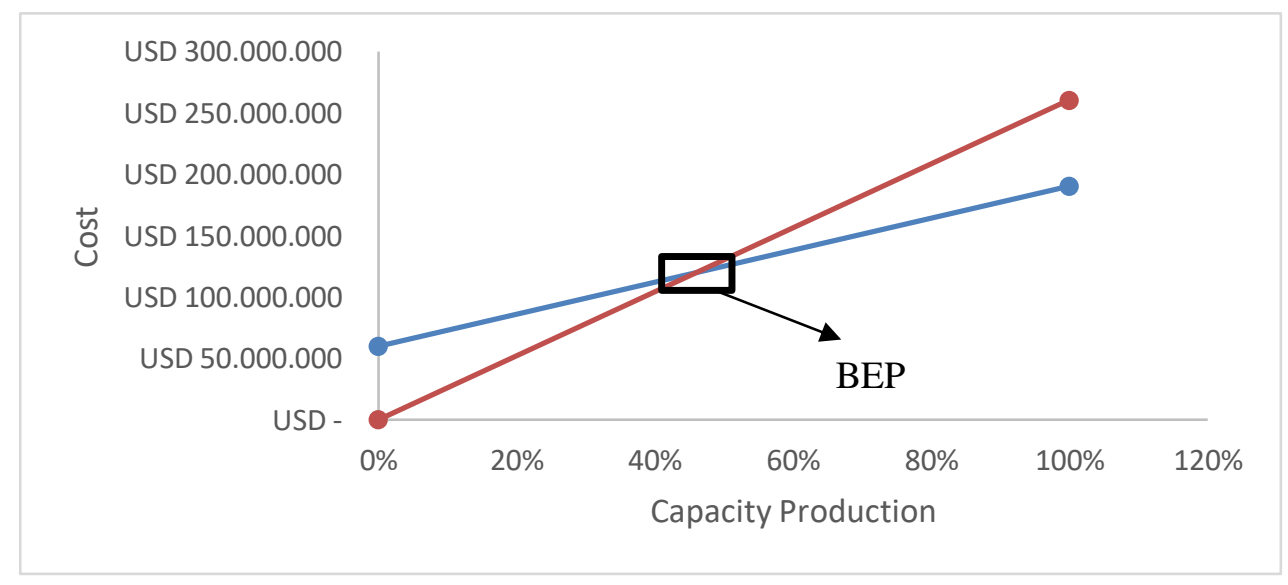

Figure 7. Break Even Point (BEP) values of CDM process based simulation. 
Based on the result calculation displayed in Figure 7, BEP values from CDM process are 46.7\%. This value equivalent as much as produce $81.8 \mathrm{MMSCFD}$. The BEP values indicate to give process that are profitable, the CDM minimum production is 81.8 MMSCFD.

\subsection{Sensitivity Analysis}

To better understand about the economy assessment, sensitivity analysis was conducted for the design variables shown in Table 7. By varying one design parameter between boundaries, while keeping the other parameters constant, the analysis could quantify the impact of individual variables on ROI and IRR from CDM process. Variable bounds were chosen based on economy considerations, as shown in Table 7. During the sensitivity analysis, the amount of feed is maintained at 300 MMSCFD, Figure 8 and Figure 9 compare the sensitivity of the various parameters on ROI and IRR.

Table 7. List of parameters and their respective bounds for sensitivity analysis.

\begin{tabular}{lcccc}
\hline Parameter & Base Value & Lower Bound & Upper Bound & $\begin{array}{c}\text { Variable } \\
\text { Changes }\end{array}$ \\
\hline Discount rate (\%) & 3.5 & 0 & 23.5 & 2.5 \\
Inflation rate (\%) & 3.5 & 0 & 23.5 & 2.5 \\
Sales volume (\%) & 100 & 0 & 10 & 10 \\
Tax rate $(\%)$ & 30 & 0 & 50 & 5 \\
Price natural gas & 100 & 0 & 150 & 10 \\
\hline
\end{tabular}

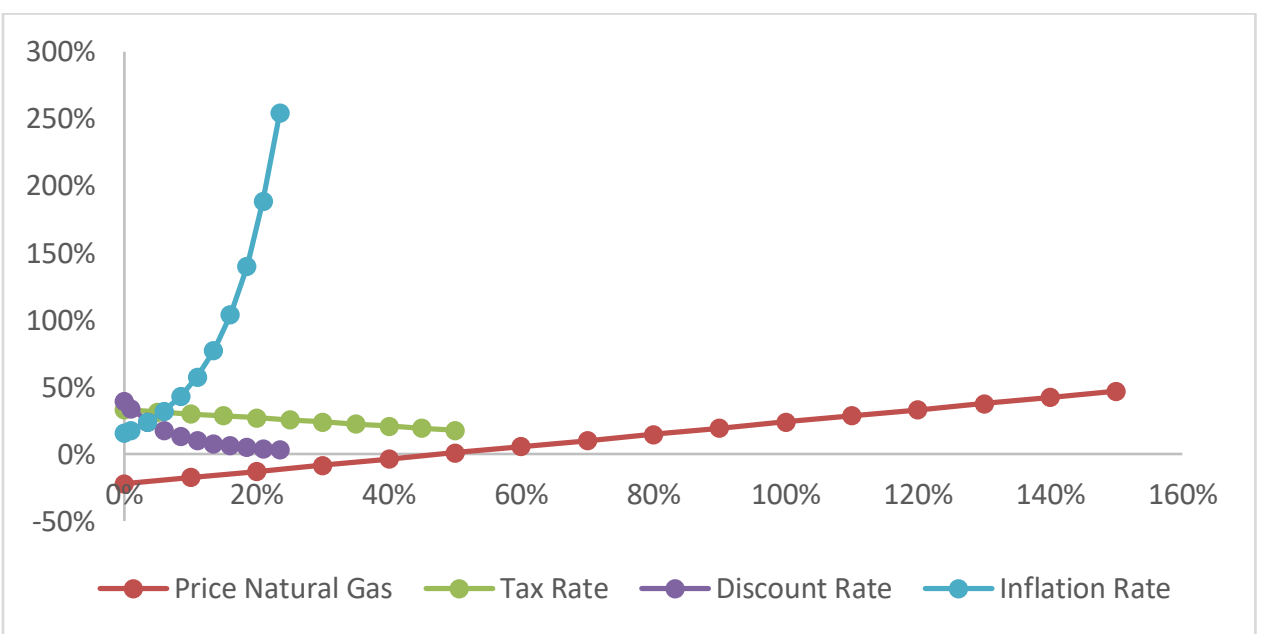

Figure 8. Sensitivity analysis of ROI based on simulation.

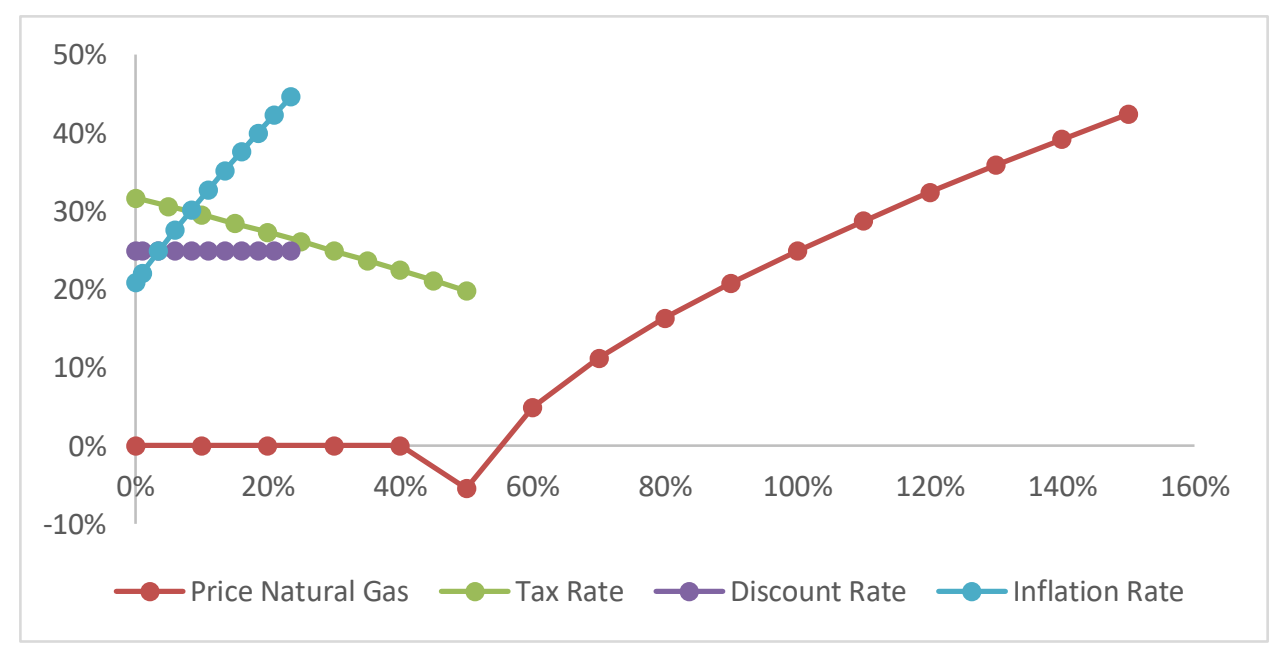

Figure 9. Sensitivity analysis of IRR based on simulation. 
Based on the result calculation displayed in Figure 8 and Figure 9, price natural gas and inflation rate give positive impact to ROI and IRR value when the price natural gas and inflation rate have a higher value. While the other value such as tax rate and discount rate can give negative impact when those value have a higher value.

\section{Conclusion}

Cryogenic distillation membrane process is proposed (considering a typical composition of $29.1 \%$ $\mathrm{CH}_{4}$ and $71 \% \mathrm{CO}_{2}$ ) in order to purify natural gas for several commercial uses. The process is validated against the previous experimental data in literature and shows well agreement. In addition, the present system introduces a new technique for mitigating $\mathrm{CO}_{2}$ freeze-out, which was a crucial barrier upon implementing cryogenic approaches. Below, the main conclusions drawn from the current report:

1. Based on the calculation through simulation using software ASPEN HYSYS, the cryogenic distillation membrane is feasible process compared to other commercial processes for natural gas purification, because it gives capture rate $\mathrm{CO}_{2}$ up to $99 \%$, decreases the purity $\mathrm{CO}_{2}$ from $70 \%$ to $0.001 \%$, reduces the purity $\mathrm{H}_{2} \mathrm{~S}$ from $0.6 \%$ to $0.02 \%$, increases natural gas purity from $28.1 \%$ to $98.85 \%$, raises the heating value from $284.5 \mathrm{Btu} / \mathrm{SCF}$ to $988.4 \mathrm{Btu} / \mathrm{SCF}$ and the hydrocarbon losses only $0.5 \%$. In addition, the specifications of natural gas products already meet the requirement of Gas Processors Suppliers Association (GPSA) standard.

2. The CDM process can purify various composition of natural gas. Based on simulation, minimum result purity for natural gas by using $\mathrm{CDM}$ are $97 \% \mathrm{CH}_{4}$. Minimum energy got from natural gas feed with composition $41 \% \mathrm{CO}_{2}$. This specifications already fulfill the standard for commercial uses.

3. The CDM process also environmentally friendly process compared to other commercial processes. From CDM process gives less emission from utilities, does not require hazardous chemicals and can utilize $\mathrm{CO}_{2}$ become liquid as valuable by-product.

4. Based on economic analysis for CDM process, the value of Capital Expenditure (CAPEX), Operational Expenditure (OPEX), Return of Investment (ROI), Break Even Point (BEP), Internal Rate of Return (IRR) and Pay Back Period (PBP) respectively are USD 344,472,322.45; USD $155,772,528.14 ; 23.8 \% ; 46.7 \% ; 24.91 \%$ and 4.21 years. From the calculation, the CDM process is economically feasible due to cheaper CAPEX, lower OPEX, higher ROI and faster payback period compared with other commercial processes.

5. Sensitivity analysis identifies main cost drivers for the process. These factors should be improved in a synergistic manner for a more economically viable process.

\section{References}

Babar, M., Bustam, M. A., Ali, A., Maulud, A. S., Shafiq, U., Mukhtar, A., Sharif, A. M. (2019). Thermodynamic data for cryogenic carbon dioxide capture from natural gas: A review. Cryogenics, 102, 85-104.

Baccanelli, M., Langé, S., Rocco, M. V., Pellegrini, L. A., \& Colombo, E. (2016). Low temperature techniques for natural gas purification and LNG production: An energy and exergy analysis. Applied Energy, 180, 546-559.

Bakar, W. A., \& Ali, R. (2010). Natural gas. Universiti Teknologi Malaysia.

Bauer, F., Hulteberg, C., Persson, T., \& Tamm, D. (2013). Biogas upgrading - Review of commercial technologies. Svenskt Gastekniskt Center.

BPPT. (2018). Outlook energi Indonesia 2018. Pusat Pengkajian Industri Proses dan Energi (PPIPE).

GPSA. (2004). GPSA engineering data book. Tusla: GSAP.

Pittalà, G. M. (2018). A study of the effect of $\mathrm{CO}_{2}$ cryogenic coolant in end milling of Ti-6Al-4V. 8th CIRP Conference on High Performance Cutting (HPC 2018), 445-448.

Purwanto, W. W., Muharam, Y., \& Pratama, Y. W. (2016). Outlook of natural gas industry development in Indonesia. Journal of Natural Gas Science and Engineering, 29, 55-65. 
Song, C., Fan, Z., Li, R., Liu, Q., \& Kitamura, Y. (2018). Efficient biogas upgrading by a novel membrane-cryogenic hybrid process experiment and simulation study. Journal of Membrane Science(565), 194-202.

Song, C., Liu, Q., Deng, S., Li, H., \& Kitamura, Y. (2019). Cryogenic-based $\mathrm{CO}_{2}$ capture technologies: State-of-the-art developments and current challenges. Renewable and Sustainable Energy Reviews, 101, 265-278.

Turton, R., Shaewitz, J. A., Bhattacharyya, D., \& Whiting, W. B. (2008). Analysis, synthesis and design of chemical processes. Upper Saddler River: Pearson Education (US).

Yeo, Z. Y., Chew, T. L., Zhu, P. W., Mohamed, A. R., \& Chai, S. P. (2012). Conventional processes and membrane technology for carbon dioxide removal from natural gas: A review. Journal of Natural Gas Chemistry, 21, 282-298.

Yousef, A. M., El-Maghlany, W. M., Eldrainy, Y. A., \& Attia, A. (2019). Upgrading biogas to biomethane and liquid $\mathrm{CO}_{2}$ : A novel cryogenic process. Fuel(251), 611-628. 